\title{
A Study on Naevi in Children in a District Hospital in North India
}

\section{Puri N*}

Consultant Dermatologist, Punjab Health Systems Corporation, India

*Corresponding author: Neerja Puri, MD (Dermatology), MD Anaesthesia, FICS, FIMSA, FCGP, Punjab Health Systems Corporation, Punjab, India, Tel: 0091-98146-16427; Email: neerjaashu@ rediffmail.com

\section{Investigation Paper}

Volume 5 Issue 3

Received Date: April 10, 2020

Published Date: August 11, 2020

DOI: $10.23880 /$ cdoaj-16000216

\section{Abstract}

Introduction: Melanocytic naevi may be congenital or acquired. Epidermal naevi are typically seen at birth or develop in early childhood. These are abnormal benign patches or plaques of brown skin.

Aims: To study various types of naevi in children below 14 years attending the dermatology OPD in a District hospital from August 2018 to August 2019.

Methods: A total of 520 paediatric patients age attending the dermatology OPD in a District hospital from August 2018 to August 2019 were screened for various types of nevi. Out of these twenty cases were found to be having naevi and were taken up for the study.

Results: There were 14 females and 6 males and female: males was 2.3:1. Onset of lesions was before 6 months in 13 patients and after 6 months in 7 patients. Family history of naevi was positive in 2 patients.The age of children ranged from 6 months to 14 years with a mean age of presentation 7 years. Multiple lesions were seen in 5 patients and single lesions were seen in 15 patients. There was variation in the size of naevi ranging from $1.5 \mathrm{~cm}$ to $22 \mathrm{~cm}$. Giant melanocytic nevus was seen in 2(10\%) children, small melanocytic naevi were seen in 10 children, nevus achromicus was seen in 2 children, Verrucous epidermal nevus was seen in $2(10 \%)$ children, Non verrucous epidermal nevus was seen in 1(5\%) child, Linear and whorled nevoid hypermelanosis was seen in $1(10 \%)$ child, Nevus Comedonicus and Nevus spilus were seen in $1(10 \%)$ child each respectively. Discussion: More comprehensive studies on morphological types and clinical spectrum of naevi need to be undertaken for proper understanding of naevi.

Keywords: Melanocytic naevi; Congenital; Acquired; Epidermal naevi; Blashko

\section{Introduction}

The naevi can be classified into congenital and acquired melanocytic naevi. The acquired melanocytic naevi are further classified into junctional, compound and intradermal naevi. Apart from these, there are several additional variants like spitz naevi, blue naevi, nevus spilus and nevus comedonicus [1]. The congenital melanocytic naevi are usually present at birth, although in a minority of cases, they may not be clinically apparent till two years of age [2]. Acquired melanocytic naevi can develop at any age, but most commonly appear after 2 years of age.
Depending on the size, congenital melanocytic naevi can be small(less than $1.5 \mathrm{~cm}$ in diameter), intermediate (Between 1.5cm-10), large (More than $20 \mathrm{~cm}$ ) and giant congenital melanocytic naevi (more than $50 \mathrm{~cm}$ ) [3]. There are also various types of epidermal naevi, which can be further classified into verrucoous and non verrucous epidermal naevi. These epidermal naevi can also be a part of syndrome known as epidermal nevus syndrome $[4,5]$. Naevi can also appear along the lines of blashko and linear and whorled nevoid hypermelanosis is one of them [6]. There are some dermal naevi like mongolion spots and nevus of ota. 


\section{Aims}

- To study various types of naevi in children below 14 years attending the dermatology OPD in a District hospital from August 2018 to August 2019.

- To study any associated anomalies.

\section{Methods}

A total of 820 paediatric patients (children below 14 years) of age attending the dermatology OPD in a District hospital from August 2018 to August 2019 were screened for various types of nevi. It was a randomized prospective hospital based study. Out of these twenty cases were found to be having naevi and were taken up for the study. Prior permission of hospital ethical committee was taken up for the study. Complete history and cutaneous examination was done in all the children and all these were recorded on a performa. Age, sex, associated symptoms, site of onset, location, duration and extent and number of lesions and family history were noted in all the children. Any extracutaneous anomalies including limb, nail and teeth anomalies were noted. Histopathological examination was performed as and when required.

\section{Results}

The data was collected, tabulated and the results were analyzed statistically.

\begin{tabular}{|c|c|c|c|}
\hline Sr No & Age Distribution & Number & Percentage \\
\hline 1 & $0-5$ Years & 14 & $70 \%$ \\
\hline 2 & $6-14$ Years & 6 & $30 \%$ \\
\hline 3 & Total & 20 & $100 \%$ \\
\hline
\end{tabular}

Table 1: Table Showing Age Distribution of Children.

\begin{tabular}{|c|c|c|c|}
\hline Sr No & Types of Nevi & Number & Percentage \\
\hline 1 & Nevus achromicus & 2 & $10 \%$ \\
\hline 2 & Melanocytic nevus (small) & 10 & $50 \%$ \\
\hline 3 & Giant melanocytic nevus & 2 & $10 \%$ \\
\hline 4 & Verrucous epidermal nevus & 2 & $10 \%$ \\
\hline 5 & Non verrucous epidermal nevus & 1 & $5 \%$ \\
\hline 6 & Linear and whorled nevoid hypermelanosis & 1 & $5 \%$ \\
\hline 7 & Nevus Comedonicus & 1 & $5 \%$ \\
\hline 8 & Nevus spilus & 1 & $5 \%$ \\
\hline 9 & Total & 20 & $100 \%$ \\
\hline
\end{tabular}

Table 2: Table Showing Types of Nevi.

\section{Discussion}

There were 14 females and 6 males and female: males were 2.3:1. Onset of lesions was before 6 months in 13 patients and after 6 months in 7 patients. Family history of naevi was positive in 2 patients. The age of children ranged from 6 months to 14 years with a mean age of presentation 7 years. Multiple lesions were seen in 5 patients and single lesions were seen in 15 patients. There was variation in the size of naevi ranging from $1.5 \mathrm{~cm}$ to $22 \mathrm{~cm}$. Giant melanocytic nevus (Figures 1 and 2) was seen in 2(10\%) children, small melanocytic naevi (Figure 3) were seen in 10 (50\%) children, nevus achromicus (Figure 4) was seen in $2(10 \%)$ children, Verrucous epidermal nevus (Figure 5) was seen in $2(10 \%)$ children, Non verrucous epidermal nevus (Figure 6) was seen in $1(10 \%)$ child, Linear and whorled nevoid hypermelanosis (Figure 7) was seen in $1(10 \%)$ child, Nevus Comedonicus (Figure 8) and Nevus spilus (Figure 9) were seen in 1 (10\%) child each respectively. Histopathology of melanocytic nevus showed nests and cords of nevus cells extending deep into dermis (Figure 10). Regarding the associated anomalies, seizures were seen in 2 patients. Regarding the site, the commonest location of naevi was head and neck area in $15(75 \%)$ children, followed by trunk in $4(20 \%)$ children and limbs in $1(5 \%)$ child.

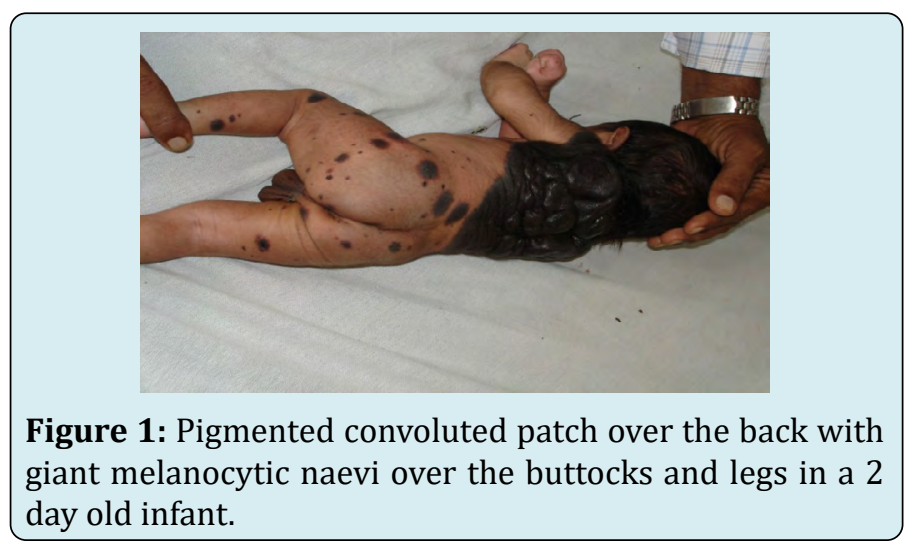




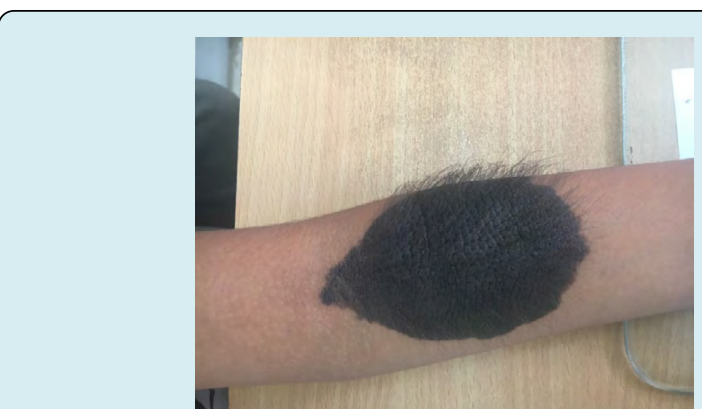

Figure 2: Hairy melanocytic nevus on a limb of 12 years old girl.

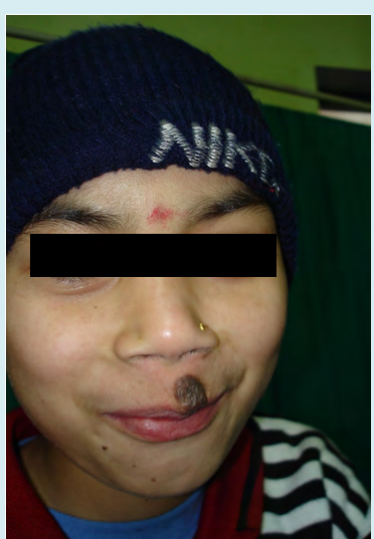

Figure 3: Melanocytic naevi on face in a 11 years old girl.

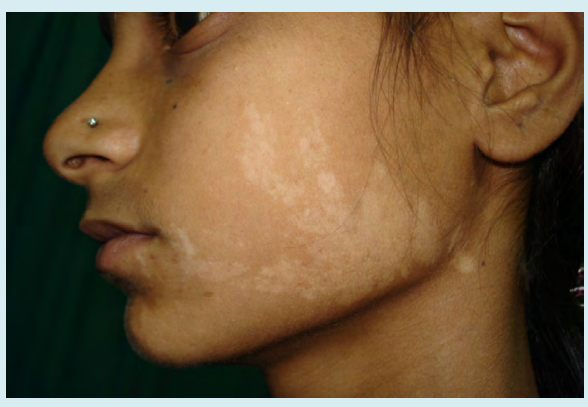

Figure 4: Nevus achromicus in a 11 years old girl.

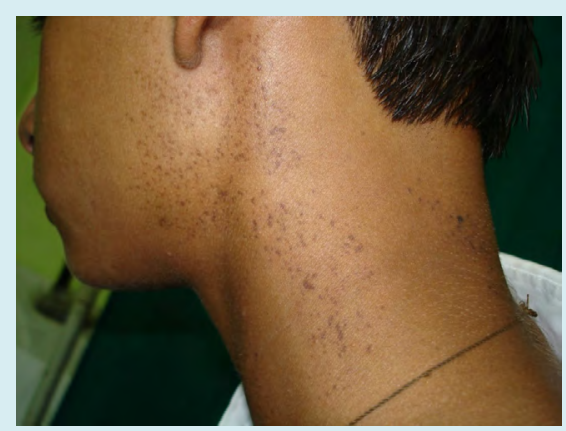

Figure 5: Verrucous epidermal naevus in a 14 years old male child.

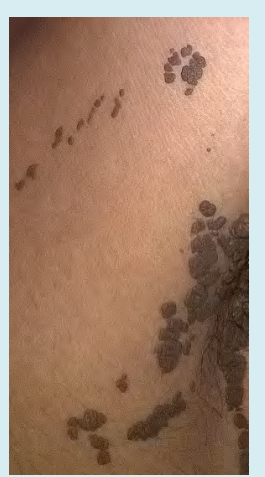

Figure 6: Non verrucous epidermal naevus in a 8 years old male child.

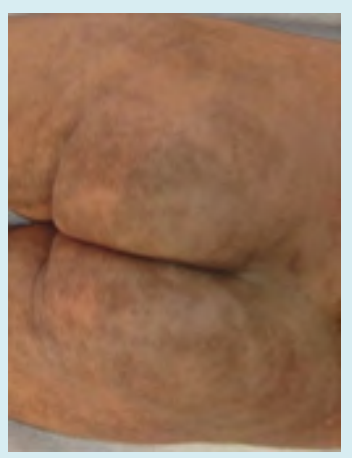

Figure 7: Linear and whorled nevoid hypermelanosis in 8 months old infant.

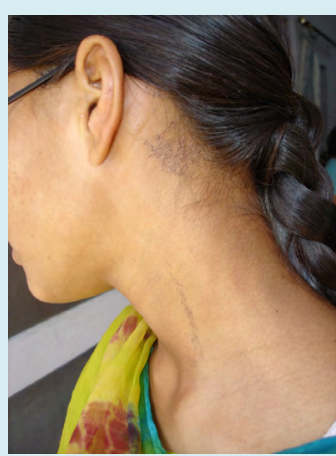

Figure 8: Nevus comedonicus in a 14 years old girl child.

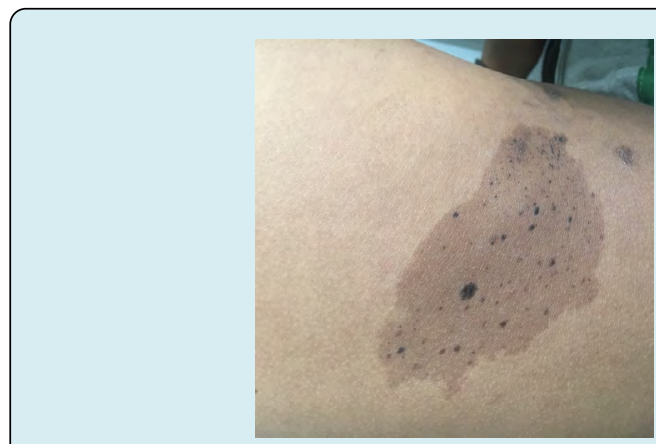

Figure 9: Nevus spilus in a 10 year old boy. 


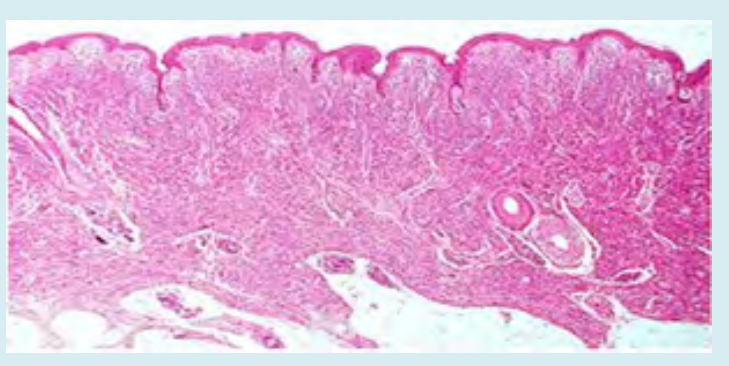

Figure 10: Photomicrograph showing nests and cords of naevus cells extending deep into dermis H\& E stain.

In our study, females outnumbered males. This was in contrast to a study of children in Colarado, where males outnumbered females [7]. The gender differences in their study could be due to variation in sun exposure or biological disposition of males to develop more naevi. Family history of naevi was positive in $2(10 \%)$ of our patients. This is in contrast to a study by Stefanaki, et al. in which family history was positive in $43.12 \%$ patients [8]. In our study, giant melanocytic naevi was seen in $2(10 \%)$ children. Out of these two cases, one infant had neurocutaneous melanocytic naevi. This is a rare disorder and it represents pigment cell tumour of leptomeninges and occurs in association with large or multiple neurocutaneous melanocytic naevi. Neurocutaneous melanocytic naevi is seen in $2-45 \%$ of patients with giant melanocytic naevi [9]. This is similar to our study in which neurocutaneous melanocytic naevi were seen in 5\% patients.Here, the melanocytic cells are found in large numbers in leptomeninges of brain and spinal cord. There are many many schools of thought of neurocutaneous melanocytic naevi though its pathogenesis is unclear. Abnormal postzygotic development of melanoblasts may be one factor in its development.

There was one case (5\%) of verrucous and one case (5\%) of non verrucous epidermal naevi in our study. Epidermal naevi are hamartomas in which there is hyperplasia of epidermis and adnexal structures and serious disfigurement can be associated with it [10]. These epidermal naevi have various subtypes like nevus comedonicus, eccrine nevus and apocrine naevi [11]. Verrucous epidermal naevi appears as verrucous papules which coalesced to form well demarcated skin colored or brownish papillomatous plaques. Most epidermal naevi measure several centimeters or less in length but can extend along the entire limb or traverse chest or abdomen [12]. There was one case of nevus achromicus (depigmentosus) in our study [13]. It is a congenital non progressive hypopigmented macule. It increases in size with the growth of the body, reaching its maximum dimensions and usually remains stable throughout life. We had one case (5\%) of linear and whorled nevoid hypermelanosis in our study. This is a rare condition with whorled hyperpigmentation along the lines of blashko and usually appears in first two years of life [14]. Its cause is developmental somatic mosaicism.

\section{Conclusion}

Our study shows various types of naevi in children below 14 years of age. Very few studies have been done encompassing all these entities of naevi. The epidemiology, distribution and clinical characteristics highlighted in our study, helps in better understanding of wide and extensive spectrum of naevi in children.

\section{References}

1. Kopf AW, Levine LJ, Rigel DS, Friedman RJ, Levenstein M (1985) Prevalence of Congenital - Nevus like Nevi, Nevi Spili and Cafı au lait spots. Arch Dermatol 121: 766-769.

2. Marghoob AA (2002) Congenital melanocytic nevi: Evaluation and management. Dermatol clin 20(4): 607616.

3. Oliveria SA, Satagopan JM, Geller AC, Dusza SW, Weinstock MA, et al. (2009) Study of Nevi in Children (SONIC): baseline findings and predictors of nevus count. Am J Epidemiol 169(1): 41-53.

4. Happle R (2010) The group of epidermal nevus syndromes. Part I. Well defined phenotypes. J Am Acad Derm 2010 63(1): 1-22.

5. Sugarman JL (2004) Epidermal nevus syndromes. Semin Cutan Med Surg 23(2): 145-157.

6. Di Lernia V (2007) Linear and whorled hypermelanosis. Pediatr Dermatol 24(3): 205-210.

7. Dodd AT, Morelli J, Mokrohisky ST, Asdigian N, Byers TE, et al. (2007) Melanocytic nevi and sun exposure in a cohort of colorado children: anatomic distribution and site-specific sunburn. Cancer Epidemiol Biomarkers Prev 16(10): 2136-2143.

8. Stefanaki C,Soura E, Stergiopoulou A, Kontochristopoulos G, Katsarou A, et al. (2018) Clinical and dermoscopic characteristics of congenital melanocytic naevi. J Eur Acad Dermatol Venereol 32(10): 1674-1680.

9. Kadonaga JN, Frieden IJ (1991) Neurocutaneous melanosis: Definition and review of literature. J Am Acad Dermatol 24(5): 747-55.

10. Dhanaraj M, Ramalingam M (2015) Systematised epidermal nevus - a case report. J Clin Diagn Res 9(2): $1-2$. 
11. Coleman WP, Gately LE, Krementz AB, Reed RJ, Krementz ET (1980) Nevi, lentigines, and melanomas in blacks. Arch Dermatol 116(5): 548-551.

12. BB Adams, DF Mutasim (1999) Adult onset verrucous epidermal nevus. J Am Acad Dermatol 41(5): 824-826.
13. Lee HS, Chun YS, Hann SK (1999) Nevus depigmentosus: Clinical features and histopathologic characteristics in 67 patients. J Am Acad Dermatol 40(1): 21-26.

14. Mendiratta V, Sharma RC, Arya L, Sardana K (2001) Linear and whorled nevoid hypermelanosis. J Dermatol 28(1): 58-59. 